\section{Anonymous peer refereeing}

SIR-Recent complaints about the flaws of anonymous peer refereeing (APR) have overlooked a crucial question: how has this system arisen? Why do authors and referees regard this practice as inherently fair, so that they never really question its ethical validity? The explanation may be an historically interesting example of the unnoticed substitution of values.

The roots of APR are likely to be found in a legitimate democratic perception of anonymous voting. Anonymous voting by, say, secret ballot, is valid when issues must be determined by anonymous majority vote, say the election of governments or departmental chairmen. Scientists as a group have a deep respect for democratic traditions. But judgement on a particular research paper is not within the domain of statistical counting and is not (or at least should not be) subjected to an anonymous peer vote. Is it possible that traditional sympathy for democratic traditions has led the scientific community spectacularly to overlook the inappropriateness of APR?

Alexander A. Berezin Department of Engineering Physics, McMaster University,

Hamilton, Ontario, Canada, L8S 4M1

SIR-I should like to add my recent experience to the letters regarding anonymous referees from A. Thyagaraja (Nature 335, 391; 1988) and J. B. Wright (Nature 336, $10 ; 1988)$. During the past year, I have submitted three reports of theoretical calculations in an active field of research to journals in three different countries. The results of the calculations differed in one significant respect from those generally accepted and publication was refused in all cases. I have no quarrel with this but, as none of the referees was able to produce experimental evidence for the rejection of the results, it was frustrating that all the reports were anonymous.

In one case, I attempted to correspond with the referee through the editor, who refused to pass on my letter as this was againat the policy of the journal. Again, I appreciate that this policy is designed to give referees more freedom to speak their mind, but I would argue that, if referees are to remain anonymous, it should be possible for an author to communicate once through the editor, after which it is up to the referee to consign the communications to the wastepaper basket if he likes.

G.C. Fletcher

Department of Physics,

Monash University,

Clayton, Victoria 3168 ,

Australia
SIR-J.B. Wright (Nature 336, 10; 1988)

does not believe there is a single good reason for anonymous refereeing, and asks for opinions from other readers. For about twenty years, I have signed all my reviews. My strong feeling is that nonanonymity helps to keep reviews brief, helpful and relevant. Anonymous reviews tend towards rambling essays on epistemology or, worse, a reviewer's opinion, based on unpublished observations, that a particular detail is inappropriate.

Few editors even read unsigned letters. None publishes them. It is therefore inexplicable to me why scientists accept anonymous reviews of their work. Some more specialized journals already publish critiques if they make interesting points not covered in the article itself. Nature might try this with some major articles, at least*. The manuscripts would be much improved, and the general reader is likely to enjoy seeing other, informed points of view. Along with Wright, I would have no confidence in a referee who balks at being identified

There is a further benefit that even the most insecure, but overworked, scientist might appreciate. Judging from a small database, it seems that insisting on having your name on all reviews substantially decreases the number of manuscripts you are asked to review.

Leidy Laboratory of Biology,

STEPHEN Roth

University of Pennsylvania,

Philadelphia,

Pennsylvania 19104-6018, USA

* For an example, see Nature 223, 161 (1969). Editor, Nature.

\section{NERC rundown}

SIR-The November 1988 issue of The Biologist made public what has been known to the Nature Conservancy Council and its advisers for some time, that the UK Natural Environmental Research Council is proposing to run down the Biological Records Centre at Monkswood, a data centre of world renown. The marine science division of NERC has already closed down the long-term biological data series for the English Channel off Plymouth - called the 'Russell Cycle' and is planning to stop the operations of the Continuous Plankton Recorder survey of the North Sea and eastern North Atlantic early next year. Both of these data series are of world-wide scientific interest, and, like the data held by the Biological Records Centre, provide important information on the effects, deleterious or otherwise, of man's influence on the biosphere.

An inescapable conclusion is that
NERC is preparing to close down most of the existing biological recording and collection of time-series data. Such continuing studies have been criticized by research council staff and civil servants on the grounds that they are "open-ended" and prevent the more "flexible" approach required by today's government. In this context, 'flexibility' means the ability of NERC administrators to direct groups of researchers towards special topics currently deemed of popular or governmental importance. Such pop topics change every few years and research would thus proceed in a series of wellpublicized short-term ad hoc projects. It seems that NERC officials have persuaded their council members to agree that biological recording is a low priority area unworthy of NERC support and that there is a plan in the United Kingdom to run down all biological work of environmental importance, especially in the marine field. It is time biologists started protesting loudly in public and began lobbying fellow biologists who have places on the research councils.

A. J. SOUTHWARD

Marine Biological Association,

Plymouth PL1 2PB, UK

\section{Folk deceptions}

SIR-In his review of Paul Barber's book Vampires, Burial, and Death: Folklore and Reality', Roy Porter remarks: " . . . this Count Dracula figure, so familiar from the movies, bears scant relation to the traditional revenant who is so powerful a presence in Central and Eastern European folk memory. Examination of recorded sightings shows the vampire was quite different ....".

As a biologist who is also interested in traditional folk culture, I have spent many years doing field work in the areas that make up Transylvania, yet I have never heard any mention of Dracula, vampires or even "revenants". And in his encyclopaedic survey of ethnohistorical concepts', T.A. Szabó Sr includes only a single reference to drakuly (meaning 'devil') and that in 1680 .

I am inclined to think that the whole Dracula story is a projection of Western European, chiefly Anglo-Saxon, ghost tradition to a distant and mysterious land. That projection has been exploited in print and in movies, best - but not first by Béla Lugosi, whose picture adorns Porter's review and who was himself a Transylvanian in a broader sense.

$$
\text { Attilla T. Szabó }
$$

Department of Biology,

Berzsenyi College,

9701 Sombathely,

Hungary

1. Porter, R. Nature 336. 283 (1988).

2. Sazbo. T.A.. Sr The Historical Thesaurus of Transvlvanian

Hungarian Vocabulary Vols I-IV (Kriterion, Bucharest. 1975-1984). 